\title{
Seeking Help for Disaster Services After a Flood
}

\author{
Jim P. Stimpson, PhD, Fernando A. Wilson, PhD, and Shawn K. Jeffries, PhD
}

ABSTRACT

Objectives: This article describes how the frequency of exposure to a flood is associated with the probability of seeking help from agencies (eg, Federal Emergency Management Agency, Red Cross) that provide disaster-related services. The article also describes the population characteristics for the people who are most likely to seek help for disaster services.

Methods: Prospective cohort data from 1735 respondents of the lowa Health Poll were used. Multivariate logistic regression was used to model the odds of seeking help from any agency for flood-related problems.

Results: Overall, most people, regardless of flood exposure, did not seek help from disaster service agencies. Disaster services were sought by $23 \%$ of respondents who experienced $1 \mathrm{flood}, 31 \%$ who have experienced 2 floods, and $26 \%$ who have experienced 3 or more floods. Multivariate adjusted odds of seeking help were associated with number of flood experiences (odds ratio [OR] 1.58), white race (OR 0.24), economic hardship (OR 1.43), urban residence (OR 0.43), and social support (OR 0.55).

Conclusions: On average, the probability of seeking disaster relief services increases with the number of flood experiences. Racial/ethnic minorities, rural residents, economically challenged individuals, and people with low levels of perceived social support may be more likely than people without these characteristics to seek services. (Disaster Med Public Health Preparedness. 2008;2:139-141)

Key Words: stress, flood, public assistance, emergencies

$\mathrm{T}$ he recent failures by public and private entities (eg, the Federal Emergency Management Agency [FEMA], the Red Cross) to provide disaster relief services during Hurricane Katrina highlight a needed area of research. Consistent with well-documented disparities in the use of health care and other public services, certain groups may be underserved for disaster relief services. ${ }^{1-6}$ For example, few survivors of Hurricane Katrina received mental health services, and vulnerable groups such as people living with low incomes and racial/ethnic minorities were the least likely to be treated. ${ }^{7-9}$ Little information is available on the demographic correlates of seeking disaster relief services.

Although there is limited information about seeking help from disaster agencies, there is a large literature on seeking mental health services after a disaster. ${ }^{6}$ Willingness to seek help is the most important predictor for receiving help. ${ }^{10}$ Use of mental health services following a disaster has also been associated with current patient status, female sex, middle age, white race, married marital status, private or public insurance, and higher incomes. ${ }^{6,11-14}$ The reasons for underuse of mental health services by certain groups are not fully understood, but some of the empirical evidence points to differences in selfesteem, sense of personal control, informal social support, stigma, and trust in formal agencies as possible mediating mechanisms. ${ }^{15-18}$
On average, few people experience disasters and most disasters are rarely experienced more than once. However, floods are an exception because people residing in flood-prone areas may be likely to experience several floods throughout their lives. There is no information about how frequency of exposure to a disaster may affect the likelihood of seeking services. Therefore, this article describes how frequency of exposure to a flood is associated with the probability of seeking help from agencies that provide disasterrelated services. The authors also describe the population characteristics for those individuals who are most likely to seek help for disaster relief services.

\section{METHODS \\ Data Source}

The present study used prospective cohort data over 2 waves of the Iowa Health Poll, a telephone survey that conducted 2406 interviews of a representative sample of Iowa in 1992. Shortly after completion of the survey, severe storms struck the US Midwest resulting in widespread flooding during the summer of 1993. At the time, the flooding was reported to be among the worst natural disasters in Iowa's history. Follow-up interviews were conducted approximately 60 days after the entire state of Iowa was declared a federal disaster area. Postflood data were collected from 1735 of the original respondents. Further details about the sample design and data can be found elsewhere. ${ }^{19,20}$ 


\section{Variables}

Flood-related services use was assessed with a binary variable: "Did you seek help from any agency for any of the problems you had because of the flood?" A qualitative follow-up question asked respondents from which agency they requested help, but few people responded to the question, leaving the results subject to selection bias. However, among the respondents who did respond, the most frequent response was FEMA followed by the Red Cross and local or state governments. To gauge the level of impact from the flood experienced by respondents, each respondent was asked to report past experience with flooding in present or prior housing; responses ranged from 0 to 3 or more times. Control variables included various measures of demographic, socioeconomic status, and psychosocial resources. Sex was a binary variable, with female as the reference category. Race was a dichotomous measure, with nonwhite as the reference category. Age and education were measured in years. Economic hardship was a summary index of 4 items that asked respondents whether in the past year they had been laid off from a job, used savings to survive financially, experienced problems paying bills on time, or experienced a substantial decline in income. Urban versus rural residence was captured with a binary variable. Self-reported health was a binary variable, with poor health as the reference. Sense of personal control was an index of 8 items that assess perception of control over good and bad outcomes. ${ }^{21}$ Social support was an index of 10 items that assess the respondent's perception that there are people in whom the respondent could confide or from whom they could receive help.

\section{Analysis Plan}

STATA version 9 SE (StataCorp, College Station, TX) was used to perform the analysis. Unadjusted percentages of people seeking help or not seeking help are presented first by the number of floods experienced. Multivariate logistic regression was used to model the odds of seeking help from any agency for flood-related problems. All of the tests were 2-tailed, and $P<.05$ was considered statistically significant.

\section{RESULTS}

Table 1 shows the unadjusted percentage of people seeking help or not seeking help by the number of flood experiences. Overall, most people in the sample, regardless of flood exposure, had not sought help from disaster relief services agen-

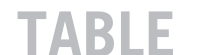

Percentage of People Seeking Help or Not Seeking Help by Number of Flood Experiences

\begin{tabular}{lcrrrr} 
& \multicolumn{2}{c}{ Did Not Seek Help } & & \multicolumn{2}{c}{ Sought Help } \\
\cline { 2 - 3 } \cline { 5 - 6 } No. of Floods & $\%$ & N & & $\%$ & N \\
0 & 90 & 522 & & 10 & 60 \\
1 & 77 & 78 & 23 & 23 \\
2 & 69 & 44 & 31 & 20 \\
$3+$ & 74 & 77 & 26 & 27 \\
Total & 85 & 721 & 15 & 130
\end{tabular}

\section{TABLE 2}

Odds of Seeking Help From Disaster Agencies for Flood-related Problems

\begin{tabular}{lccc} 
& OR & $\mathbf{9 5 \%} \mathbf{C l}$ & $\boldsymbol{P}$ \\
Flood experience & 1.58 & $1.33-1.87$ & $<.0001$ \\
Age & 0.99 & $0.98-1.01$ & .424 \\
Female & 1.02 & $0.66-1.57$ & .931 \\
White & 0.24 & $0.14-0.43$ & $<.0001$ \\
Education & 1.01 & $0.86-1.18$ & .924 \\
Economic hardship & 1.43 & $1.19-1.72$ & $<.0001$ \\
Urban & 0.43 & $0.27-0.70$ & .001 \\
Healthy & 0.96 & $0.62-1.48$ & .842 \\
Sense of personal control & 1.30 & $0.84-2.01$ & .234 \\
Social support & 0.55 & $0.35-0.87$ & .011 \\
-2 log likelihood & & 641.77 & \\
$\chi^{2}(d f)$ & & $85.78(10)$ & \\
\hline
\end{tabular}

$\mathrm{OR}=$ odds ratio; $\mathrm{Cl}=$ confidence interval; $d f=$ degrees of freedom

cies. Among respondents who have never experienced a flood, 10\% reported seeking help for disaster relief; $23 \%$ of respondents who experienced 1 flood reported that they sought disaster relief services. Among the respondents who have experienced 2 floods, 31\% sought services and for those who have experienced 3 or more floods, $26 \%$ sought services.

Multivariate adjusted odds (OR) of seeking help from disaster agencies for flood problems are shown in Table 2. Number of flood experiences was associated with higher odds of seeking help (OR 1.58). Other statistically significant predictors of seeking help were white race (OR 0.24), economic hardship (OR 1.43), urban residence (OR 0.43), and social support (OR 0.55). Interaction effects were explored for number of flood experiences and significant predictors, but none were statistically significant. Therefore, there is not sufficient evidence to suggest that the likelihood of seeking disaster relief services is conditional on flood exposure and population characteristics.

\section{DISCUSSION}

The first aim of the present study was to assess the association between frequency of exposure to a flood and the probability of seeking help from disaster agencies such as FEMA and the Red Cross. The findings suggest that the probability of seeking disaster relief services increases with the number of flood experiences. Although there are no known studies of this association, this finding is consistent with the literature on seeking psychiatric services following a traumatic event. This literature suggests that frequency of exposure to traumatic or stressful events increases the probability of seeking services in part because those events increase the need for services. $6,7,9,11-18$ Experiencing trauma is not only associated with higher risk of mental health problems but it also lowers the capacity for individuals to cope with stress by reducing the psychosocial resources available to combat stress. Applied to disaster relief services, individuals may have the resources such as family support, flood insurance, and personal savings to cope with 1 flood. However, additional floods will tap into an increas- 
ingly lower supply of resources until individuals may have no other recourse other than to seek outside assistance.

Given that the probability of seeking services may vary with the level of resources available to cope with the disaster, the second objective of the present study was to identify population characteristics for those people who are most likely to seek help for disaster relief services. The findings suggest that racial/ethnic minorities, rural residents, people experiencing economic hardship, and individuals with low levels of perceived social support are more likely than people without these characteristics to seek help from disaster agencies. Consistent with other literature on help seeking for trauma, people from a disadvantaged social status on average have fewer resources to cope with disasters and therefore may have few options other than external support from government or nonprofit groups. ${ }^{1-3}$ By extension, a reasonable hypothesis may be that the likelihood of seeking services is conditional on both social status and frequency of exposure to a disaster. The data used for our study could not support this hypothesis, but future research should test whether individuals who are most in need of services may be less inclined to seek help.

One of the strengths of the study was the use of a rare data source that followed a representative sample of people before and after a natural disaster. However, 2 limitations were few people experienced significant flood exposure and the sample was drawn from Iowa rather than from a national sample. By extension, it is possible that some of the respondents most affected by flooding could not be located for the follow-up interview. The data did not show whether respondents carried flood insurance, which would likely be an important predictor of the need for assistance. Therefore, this study should be replicated with national samples that track respondents after a disaster, preferably linked with data on insurance and geographic characteristics.

In conclusion, on average, the probability of seeking disaster relief services increases with the number of flood experiences. The most likely reason for the association of help seeking and number of exposures is increased need for services. Vulnerable populations such as racial/ethnic minorities, rural residents, and people facing economic challenges may be more likely to seek services. Service agencies should be aware that vulnerable populations may have a greater need for the services that they provide.

\section{About the Authors}

Dr Stimpson is Assistant Professor, Department of Social and Behavioral Sciences, Dr Wilson is Assistant Professor, Department of Health Management and Policy, School of Public Health, and Dr Jeffries is Assistant Professor, Department of Psychology, School of Public Health, Social, and Behavioral Sciences, University of North Texas Health Science Center.

Address correspondence and reprint requests to Jim P. Stimpson, PhD, Department of Social and Behavioral Sciences, University of North Texas Health Science Center, 3500 Camp Bowie Blvd, Fort Worth, TX 76107-2699 (e-mail: jstimpso@hsc.unt.edu).

This article is based on research that was supported by the National Institute of Mental Health (MH48165).

Received for publication February 18, 2008; accepted June 18, 2008.

\section{Authors' Disclosures}

The authors report no conflicts of interest.

ISSN: 1935-7893 (C) 2008 by the American Medical Association and Lippincott Williams \& Wilkins.

DOI: $10.1097 / \mathrm{DMP} .0 \mathrm{~b} 013 \mathrm{e} 318183 \mathrm{cfbb}$

\section{REFERENCES}

1. Fothergill A. Gender, risk, and disaster. Int J Mass Emerg Disasters. 1996;14:33-56.

2. Fothergill A, Maestas E, Darlington JD. Race, ethnicity and disasters in the United States: a review of the literature. Disasters. 1999;23:156-173.

3. Fothergill A, Peek LA. Poverty and disasters in the United States: a review of recent sociological findings. Natural Hazards. 2004;32:89-110.

4. Fiscella K, Franks P, Doescher MP, Saver BG. Disparities in health care by race, ethnicity, and language among the insured: findings from a national sample. Med Care. 2002;40:52-59.

5. Kirby JB, Taliaferro G, Zuvekas SH. Explaining racial and ethnic disparities in health care. Med Care. 2006;44:64-72.

6. Norris FH, Alegria M. Mental health care for ethnic minority individuals and communities in the aftermath of disasters and mass violence. CNS Spectr. 2005;10:132-140.

7. Brodie M, Weltzien E, Altman D, Blendon RJ, Benson JM. Experiences of hurricane Katrina evacuees in Houston shelters: implications for future planning. Am J Public Health. 2006;96:1402-8.

8. Eisenman DP, Cordasco KM, Asch S, Golden JF, Glik D. Disaster planning and risk communication with vulnerable communities: lessons from Hurricane Katrina. Am J Public Health. 2007;97:S109-15.

9. Wang PS, Gruber MJ, Powers RE, et al. Mental health service use among Hurricane Katrina survivors in the eight months after the disaster. Psychiatr Serv. 2007;58:1403-1411.

10. Gourash N. Help-seeking: a review of literature. Am J Community Psychol. 1978;6:413-423.

11. Adams ML, Ford JD, Dailey WF. Predictors of help seeking among Connecticut adults after September 11, 2001. Am J Public Health. 2004;94:1596-1602.

12. Boscarino JA, Adams RE, Figley CR. Mental health service use 1-year after the World Trade Center disaster: implications for mental health care. Gen Hosp Psychiatry. 2004;26:346-358.

13. Domino ME, Fried B, Moon Y, Olinick J, Yoon J. Disasters and the public health safety net: Hurricane Floyd hits the North Carolina Medicaid program. Am J Public Health. 2003;93:1122-1127.

14. Goto T, Wilson JP, Kahana B, Slane S. PTSD, depression and helpseeking patterns following the Miyake Island volcanic eruption. Int J Emerg Ment Health. 2002;4:157-171.

15. Norris FH, Friedman MJ, Watson PJ. 60,000 disaster victims speak: II. Summary and implications of the disaster mental health research. Psychiatry. 2002;65:240-260.

16. Husaini B, Moore S, Cain V. Psychiatric symptoms and help-seeking behavior among the elderly: an analysis of racial and gender differences. J Gerontol Soc Work. 1994;21:177-195.

17. Kaniasty K, Norris FH. Help-seeking comfort and receiving social support: the role of ethnicity and context of need. Am J Community Psychol. 2000;28:545-581.

18. Hoyt DR, Conger RD, Valde JG, Weihs K. Psychological distress and help seeking in rural America. Am J Community Psychol. 1997;25:449470 .

19. Ginexi EM, Weihs K, Simmens SJ, Hoyt DR. Natural disaster and depressive symptoms: a prospective investigation of reaction to the 1993 Midwest floods. Am J Community Psychol. 2000;28:495-518.

20. Stimpson JP. Flood and psychological well-being: direct, mediating, and moderating effects. Int J Mass Emerg Disasters. 2005;23:27-48.

21. Mirowsky J, Ross CE. Eliminating defense and agreement bias from measures of the sense of control: a $2 \times 2$ index. Soc Psychol Q. 1991;54:127-145. 